\title{
LITERATURA E INTERSECCIONALIDADE: "A RESPOSTA", DE KATHRYN STOCKETT, E OS LUGARES DE FALA SUBALTERNOS
}

LITERATURE AND INTERSECCTIONALITY: KATHRYN STOCKETT’S “THE HELP” AND THE SUBALTERN VOICES

\section{Ana Paula Moritz}

Mestre em Ciências Sociais pela Pontifícia Universidade Católica do Rio de Janeiro (PUC-RJ). Desenvolveu esta pesquisa ao longo da graduação como parte do Programa de Iniciação Científica A Escrita da Antropologia e o Ensaio, do qual foi integrante entre 2014 e 2015. 


\section{RESUMO}

O presente trabalho busca, por meio da análise do romance A resposta (2009), de Kathryn Stockett, explorar questões relativas à antropologia e à sociologia, bem como suas relações com a literatura. A temática do livro aborda as relações e tensões entre patroas brancas e empregadas negras do sul dos Estados Unidos nos anos 1960. Intentou-se aqui examinar lugares de fala e de identidade subalternos, a força de sua representatividade e de sua ausência na arte, situando questões dialógicas e de discurso. Com a teoria literária, a etnografia, os estudos póscoloniais e a teoria feminista é possível desconstruir a imagem romantizada dos livros, constatar seu poder de opressão e inferir que estão fortemente imbricados em um processo de silenciamento de vozes marginalizadas, femininas, negras e pobres.

PALAVRAS-CHAVE: literatura; antropologia; interseccionalidade; feminismo.

\section{ABSTRACT}

The present work seeks, through the analysis of the romance The Help (2009) written by Kathryn Stockett, research issues concerning anthropology, sociology, as well as their relation to literature. The book attends to the relations and tensions between white female employers and black female house employees in the South of the United States during the 1960's. Aiming for the examination of the strength of representation, as well as the lack of it, at the field of the arts and grounding dialogical and discourse matters, in conjunction with subaltern subjects coming to voice. With the assistance of literary theory, ethnography, post-colonial studies and feminist theories, it is possible to deconstruct the romanticized image of books, and realize its power of oppression, inferring that those are strongly connected to the process of silencing marginalized voices that belong to black poor females.

KEYWORDS: literature; anthropology; intersectionality; feminism. 


\section{Introdução}

A discussão proposta neste trabalho se dá a partir da leitura do romance $A$ resposta, de Kathryn Stockett, livro que inspirou o filme Histórias cruzadas (2012). O objetivo aqui é refletir sobre como a arte, no caso, a literatura, é cúmplice de um sistema de representatividade excludente e silenciador. Ao analisar esse sistema com base na crítica feminista interseccional e na crítica pós-colonial, desvelam-se discursos e práticas estéticas em busca da polifonia, mediante a qual se propicia a todos o espaço e o direito de falar por si.

\section{Teoria e contexto}

A teoria literária propõe diferentes formas de se ler as narrativas através de grandes chaves teóricas. Para explorar as questões propostas neste artigo foram escolhidas as teorias queer e feminista, com o objetivo a priori de pensar a performance de gênero como algo presente também em personagens ficcionais, em seu impacto nas identificações e em sua forma de representar o real.

A expansão do contexto das obras literárias evidenciada por Jonathan Culler é fruto da mudança na forma de interpretação desses textos causada pela introdução de "novas" teorias no campo. O conceito de linguagem performativa apresentado pelo autor caracteriza o discurso literário visto que seu vínculo entre sentido e intenção do falante é rompido, posto que os atos são realizados através de palavras e guiados por convenções sociais e linguísticas, e não determinados pela intenção. A linguagem literária tanto diz quanto faz; as obras literárias criam ideias e conceitos que se convertem em prática (CULLER, I999).

\footnotetext{
A performativa traz para o centro do palco um uso da linguagem anteriormente considerado marginal - um uso ativo, criador do mundo, da linguagem, que se assemelha à linguagem literária - e nos ajuda a conceber a literatura como ato ou acontecimento. A noção de literatura como performática contribui para uma defesa da literatura: a literatura não é uma pseudodeclaração frívola, mas assume seu lugar entre os atos de linguagem que transformam o mundo, criando as coisas que nomeiam. (CULLER, 1999, p. 97)
}

Ou seja, "a linguagem é performativa no sentido de que não apenas transmite informação, mas realiza atos através de sua repetição de práticas discursivas ou de maneiras de fazer as coisas estabelecidas" (CULLER, I999, p. 99). O conceito exposto relaciona a performativa com o problema geral dos atos que dão origem e criam algo novo, tanto na esfera política quanto na esfera literária. Em explicação, o autor estabelece que: 
Tanto o ato político quanto o literário dependem de uma combinação complexa, paradoxal, da performativa e da constativa, em que, para ser bem-sucedido, o ato deve convencer, referindo-se a estados de coisas em que o sucesso consiste em criar a condição à qual se refere. As obras literárias afirmam falar-nos sobre o mundo, mas, se são bem-sucedidas, o são através da criação dos personagens e acontecimentos que relatam. Algo semelhante está em ação nos atos inaugurais da esfera política. (CULLER, I999, p. 99)

O autor faz referência a Judith Butler e seu livro Gender trouble (1990), no qual a autora propõe analisar o gênero como performativo ou como uma condição encenada. $O$ gênero é criado pelos atos, de modo que cada qual se torna homem ou mulher através de atos repetidos, de acordo com a linguagem performativa explicada por Culler. Há maneiras socialmente estabelecidas de ser homem ou mulher. Desse modo, o gênero não é uma escolha, e sim uma condição de inteligibilidade do sujeito, que se dá através de práticas reiterativas e citacionais, normas repetidas compulsoriamente que animam e limitam o sujeito. Contudo também são espaços de resistência, subversão e deslocamento. Pelo fato de os corpos nunca se contentarem por inteiro dentro dessas práticas normativas, as lacunas significam espaços de resistência e possibilidade de mudança.

O modelo performativo, segundo Butler, pode ser instrumentalizado para se pensar processos sociais cruciais, como a natureza da identidade e sua produção; o funcionamento das normas sociais; a questão da agência - em que medida e sob quais condições se pode ser um sujeito responsável pelos próprios atos -; e a relação entre o indivíduo e as mudanças sociais (CULLER, 1999). Pode-se considerar uma obra bem-sucedida aquela que não se mantém como ato singular, mas que através da repetição dá vida às formas que repete e que possivelmente muda a história. Culler (1999, p. I06), ao concluir sua explicação sobre a performativa, afirma que:

O modelo da performativa oferece uma explicação mais sofisticada de questões que são muitas vezes cruamente afirmadas como um embaçamento das fronteiras entre fato e ficção. E o problema do acontecimento literário, da literatura como ato, pode oferecer um modelo para pensar os acontecimentos culturais, de modo geral.

A materialidade dos corpos literários representa muito mais do que meras personagens. O poder presente no discurso, no que concerne a formação de humanos, através de identidades e identificações daquilo que seria mais humano, menos humano, inumano ou humanamente impensável ilustra as limitações e a exclusão as quais se está sujeito. Os corpos negros são vexados. Eles não se materializam livremente, são frutos de práticas reiterativas 
e citacionais que os colocam incansavelmente em papéis servis. O corpo feminino negro, quando encontrado na literatura, na maior parte das vezes está associado a papéis nos quais atuam como personagens subservientes, e não por sua vontade, obviamente, mas pelo fato de pessoas brancas sempre as escreverem nesse lugar.

Desse modo, segundo Judith Butler(2000, p. I67):

A performatividade não é, assim, um "ato" singular, pois ela é sempre uma reiteração de uma norma ou de um conjunto de normas. E na medida que ela adquire o status de ato no presente, ela oculta ou dissimula as convenções das quais ela é uma repetição. Além disso, esse ato não é primariamente teatral; de fato, sua aparente teatralidade é produzida na medida em que sua historicidade permanece dissimulada (e, inversamente, sua teatralidade ganha uma certa inevitabilidade, dada a impossibilidade de uma plena revelação de sua historicidade).

A autora, em seguida, propõe o seguinte questionamento:

Em que medida o discurso adquire autoridade para produzir o que nomeia através da citação das convenções de autoridade? E um sujeito aparece como autor de seus efeitos discursivos na medida em que a prática citacional pela qual ele ou ela é condicionado e mobilizado permanece não marcada? Poderia ocorrer, na verdade, que a produção do sujeito como capaz de dar origem a seus efeitos é precisamente uma consequência dessa citacionalidade dissimulada? (BUTLER, 2000, p. I67)

O processo de materialização desses corpos será uma espécie de citacionalidade, isto é, a aquisição do ser através da citação do poder, uma citação que estabelece uma cumplicidade originária com o poder (BUTLER, 2000). No entanto, os processos identificatórios exigidos para possibilitar a materialização e a formação do sujeito não representam a todos.

Uma preocupação constante na literatura são as questões de identidade, para as quais as obras literárias são capazes de esboçar respostas tanto implícitas quanto explícitas. A influência das teorias de raça, de gênero e de sexualidade no campo literário enriquecem as discussões acerca das diferentes leituras que se tornam possíveis no que concerne à construção da identidade. Jonathan Culler (I999, p. III) vai além, ao alegar que:

A literatura não apenas fez da identidade um tema; ela desempenhou um papel significativo na construção da identidade dos leitores. O valor da literatura há muito tempo foi vinculado às experiências vicárias dos leitores, possibilitando-lhes saber como é estar em situações específicas e desse modo conseguir a disposição para agir e sentir de certas maneiras. As 
obras literárias encorajam a identificação com os personagens, mostrando as coisas do seu ponto de vista. Os poemas e os romances se dirigem a nós de maneira que exigem identificação, e a identificação funciona para criar identidade: nos tornamos quem somos nos identificando com as figuras sobre as quais lemos. [...]

Michael Foucault sugere que em toda sociedade a produção do discurso é controlada e, por meio de diversos procedimentos, cumpre sua função de disseminar seus poderes. Em uma sociedade como a norte-americana dos anos 1960 os negros não tinham direito à voz, apesar do lema: "separados, mas iguais". Desse modo, nas palavras do próprio Foucault, "o discurso não é simplesmente aquilo que traduz as lutas ou os sistemas de dominação, mas aquilo porque, pelo que se luta, o poder do qual nos queremos apoderar" (FOUCAULT, 2OI 2, p. IO).

No entanto é mister refletir acerca de certas normas que perduram e dão continuidade a processos e práticas performativas - reiterativas e citacionais. Por que ainda existe pouquíssimo espaço para vozes vindas das margens? Por que a representatividade de inúmeros grupos beira a inexistência? Por que sempre se busca a história única para se contar? Por que certas vozes são mais autorizadas para contar histórias do que outras?

\section{Enredo e análise de A resposta, de Kathryn Stockett}

O romance se passa na cidade de Jackson, no Mississippi (EUA), em I962, momento em que a segregação racial e os movimentos sociais de luta pelos direitos civis estão no auge. É narrado por três mulheres: Eugenia "Skeeter" Phelan, Aibileen Clark e Minny Jackson.

Skeeter é uma jovem branca de 22 anos que acaba de voltar para casa após terminar seus estudos na Universidade Ole Miss. Ao chegar, ela pergunta por Constantine, a empregada negra que a criou. No entanto seus pais se recusam a contar-lhe a verdade sobre o que aconteceu com a mulher e o motivo de sua partida. Com isso, Skeeter inicia uma busca por informações, conversando com as empregadas domésticas que trabalhavam para suas amigas. À medida que vai se aproximando delas, se sente cada vez mais impelida a questionar a segregação racial, até que decide escrever um livro com o depoimento dessas mulheres sobre suas vivências trabalhando na casa de famílias brancas.

A autora de A resposta, após receber muitas críticas, adicionou ao fim do livro um pequeno capítulo chamado "Muito pouco, muito tarde - Kathryn Stockett, por ela mesma", no qual narra sua experiência de mulher branca que teve uma empregada negra no Mississippi. 
A Resposta é, na maior parte, ficção. Ainda assim, enquanto escrevia me questionei muito sobre o que minha família pensaria do livro, e sobre o que Demetrie pensaria, também, apesar de que ela já havia morrido. Tive medo, uma grande parte do tempo, de estar ultrapassando um limite, ao escrever na voz de uma mulher negra. Eu tinha medo de falhar ao tentar descrever uma relação que era tão intensamente influente na minha vida, tão amorosa, tão grosseiramente estereotipada na história e na literatura americanas.

No que concerne à forma do romance estudado, é possível notar que se trata do que Bakhtin chama de um "romance polifônico". Ao investigar as obras de Dostoiévski nas quais o autor se relaciona com a própria criação da personagem, observa-se que a estrutura de seus romances consiste em uma polifonia de vozes independentes em que cada uma pode ser entendida a partir do interior da própria visão de mundo, e não arbitrariamente fundida em uma única posição dominante (monológica) do autor (FRANK, 1992). Ademais Dostoiévski foi pioneiro em um estilo de escrita que faz com que as vozes das personagens estejam profundamente interligadas, bem como a voz do autor tenha tanto peso quanto a de qualquer uma das personagens.

O "discurso de dupla voz" merece especial atenção, pois é o uso linguístico afetado e deflectido pela consciência do discurso do outro(FRANK, 1992). Joseph Frank (1992, p. 32-33), comentador da obra de Bakhtin, afirma que:

Nesta análise, Bakhtin está primeiramente interessado em ilustrar as várias maneiras pelas quais as figuras centrais de Dostoiévski reagem contra todas as tentativas de restringir e confinar a liberdade de suas personalidades, $\mathrm{e}$ também em analisar vários tipos de discurso de voz dupla pelos quais elas assimilam as vozes de outros e respondem a elas de forma fortemente afetada por tal assimilação.

Compreende-se, então, que essa forma de discurso abarca o dito e o não dito. Os discursos e os silêncios estão deliberadamente postos nas palavras daqueles que convém ouvir e daqueles que convém calar. O discurso hegemônico encontra-se presente em todos os discursos construídos. No entanto a liberdade descrita por Bakhtin nos romances de Dostoiévski mostra o início de um deslocamento das vozes. No que se refere ao romance A resposta, é possível perceber ao longo da narrativa o nascimento e o crescimento da voz das personagens principais, até o momento em que essas vozes transbordam a oralidade e se transformam em narrativa escrita.

A questão da autoridade etnográfica pode ser utilizada para discutir e ilustrar essa problemática que envolve as diversas vozes, tanto na literatura quanto na antropologia e na etnografia. James Clifford (2008), ao escrever sobre a autoridade etnográfica, questiona os 
paradigmas desse tipo de escrita. $\mathrm{O}$ autor, em referência a Bakhtin, ressalta que uma condição fundamental do romance polifônico é que ele representa sujeitos falantes em um campo de múltiplos discursos.

O romance luta com, e encena, a heteroglossia. Para Bakhtin, preocupado com a representação de todos não homogêneos, não há nenhum mundo cultural ou linguagem integrados. Todas as tentativas de propor tais unidades abstratas são constructos do poder monológico. Uma "cultura" é concretamente um diálogo em aberto, criativo, de subculturas, de membros e não membros, de diversas facções. (CLIFFORD, 2008, p. 47)

Assim, ainda nas palavras de James Clifford (2008, p. 47-48):

A etnografia, como o romance, debate-se entre essas alternativas. Será que o escritor etnográfico retrata o que os nativos pensam à maneira do flaubertiano "estilo indireto livre", um estilo que suprime a citação direta em favor de um discurso controlador que é sempre, mais ou menos, o do autor? Ou será que o retrato de outras subjetividades requer uma versão estilisticamente menos homogênea, cheia das "vozes diferentes" de Dickens?

A questão levantada por Clifford é de grande importância, pois se aplica tanto a um problema do fazer etnográfico/antropológico quanto do fazer literário. $\mathrm{O}$ autor reconhece que o estilo indireto vem sendo usado pela etnografia e pelo romance em diferentes níveis de abstração, quando, por exemplo, não podemos nos perguntar como Flaubert sabe o que Emma Bovary está pensando (CLIFFORD, 2008). No entanto, na escrita etnográfica, antropólogos/etnógrafos vêm atribuindo valores subjetivos às culturas. Tais declarações não têm "nenhum falante específico" (SPERBER, I98I apud CLIFFORD, 2008, p. 48) e são literalmente equivocadas, combinando de maneira contínua as informações do etnógrafo e/ou dos informantes. O autor ainda critica aquelas etnografias que fazem assunções na voz de ninguém e dessa maneira acabam por assumir a voz da cultura.

Tendo em vista tais argumentos é possível pensar que a autora de A resposta, ao produzir nessa obra um romance anônimo, tentava se desvencilhar dessas "armadilhas" do estilo indireto, porém, por se tratar de um romance dentro de outro romance do qual ela é a autora, a voz que se manifesta será sempre a dela. Sua voz sempre será a que controla os discursos ali produzidos e enunciados, acabando por roubar o protagonismo das outras vozes que deveriam estar presentes mais fortemente em seu romance: das mulheres negras que trabalhavam como empregadas domésticas em casas de famílias brancas no Mississippi, em 1962.

A ausência do outro, a dupla alteridade e a abjeção dessas mulheres em relação aos seus corpos e às suas vozes nos remetem à pergunta de Gayatri Spivak (20I0): Pode o subalterno 
falar? A autora constrói seus argumentos com base em uma crítica de Gramsci e sugere resgatar e retomar o significado do termo "subalterno", que se refere ao "proletariado", ou seja, aquele cuja voz não pode ser ouvida. Argumenta que o termo "descreve as camadas mais baixas da sociedade constituídas pelos modos específicos de exclusão dos mercados, da representação política e legal e da possibilidade de se tornarem membros plenos no estrato social dominante" (ALMEIDA, 20IO apud SPIVAK, 20IO, p. I3).

A mulher subalterna não pode falar e quando se arrisca fazê-lo não encontra meios de se fazer ouvir. O agenciamento que ocorre de maneira validada institucionalmente impossibilita uma representação efetiva e significativa que impede a articulação de discursos e atos de resistência fora daqueles que são hegemônicos (ALMEIDA, 2OIO apud SPIVAK, 20IO).

Para corroborar com os argumentos tecidos até então, apresento um exemplo dos dados quantitativos encontrados ao longo da pesquisa que ilustram a falta de representatividade da mulher no campo literário. O Gráfico I divide os ganhadores do prêmio Pulitzer, principal prêmio literário do mundo, do ano 2000 até 2015, por gênero do autor e gênero das personagens.

\section{Gráfico 1. Prêmios Pulitzer 2000-2015: autores e autoras ganhadores e sobre quem são} suas histórias.

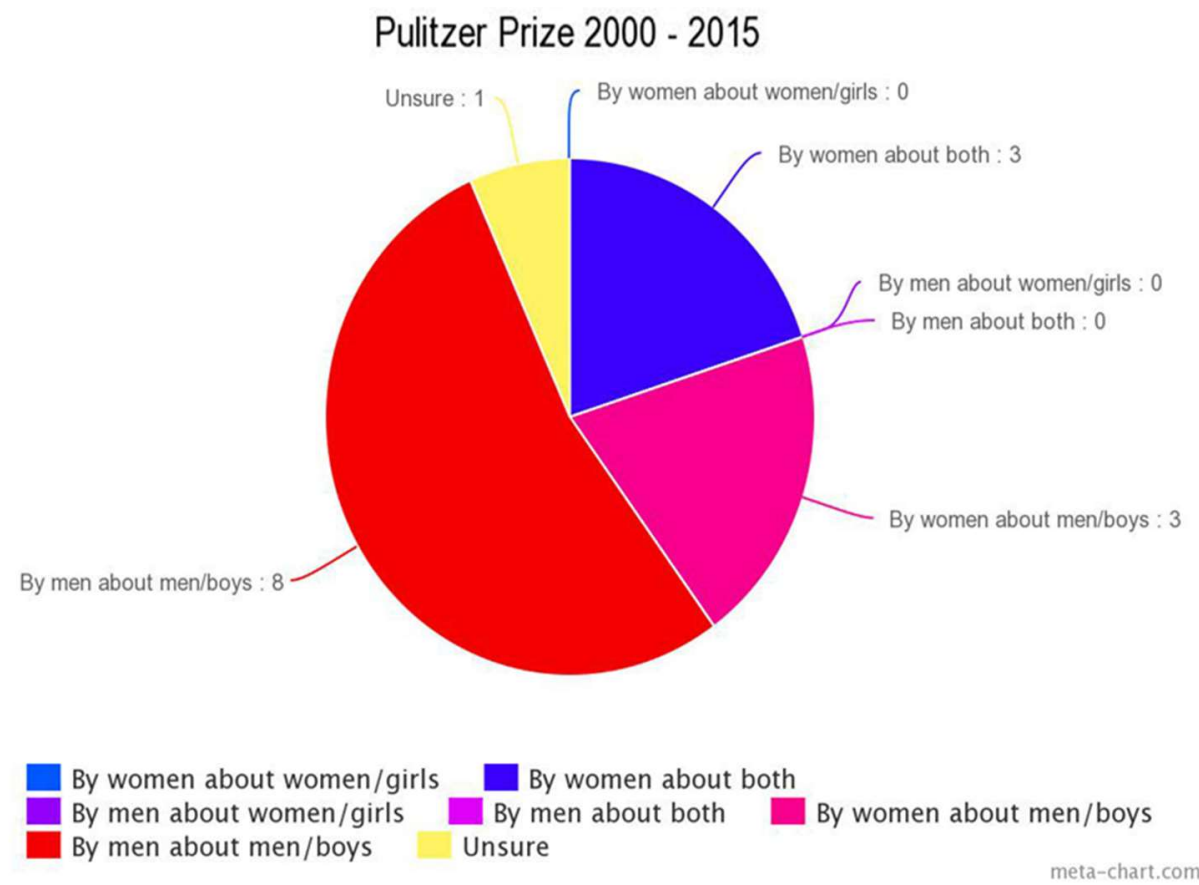


A representação e a representatividade feminina e a presença da mulher tanto nas temáticas quanto na enunciação e na escrita de livros ainda acontecem de maneira tímida, principalmente nos livros premiados. Esse dado reforça a afirmação de Spivak (2010) de que o subalterno como sujeito feminino não pode ser ouvido ou lido.

\section{Interseccionalidade e a mulher negra na literatura}

Interseccionalidade é o estudo das intersecções entre formas ou sistemas de opressão, dominação ou discriminação. Tem como principal exemplo o feminismo negro, que disserta sobre as experiências de ser mulher e negra, e o quão interligadas essas experiências estão, de modo que não é possível considerá-las individualmente pelo fato de estarem sobrepostas na hierarquia marginalizante da sociedade.

Questionar essas estruturas para que os sujeitos do feminismo não sejam novamente excluídos dentro da universalização da categoria mulher é de extrema relevância, pois, se de acordo com Beauvoir (2009), não se nasce mulher, mas torna-se; e conforme a teoria de Judith Butler(20I4), ser mulher é um constructo, e o gênero, performance, é impreterível que se faça representar a todas as mulheres em sua especificidade, tanto na teoria quanto na prática. Pensar as intersecções é desafiar as estruturas de poder e lutar contra o silenciamento de vozes.

A teoria social crítica contida no feminismo negro norte-americano emerge como um movimento contra as injustiças sociais que ocorriam/ocorrem tanto contra mulheres negras quanto com outros grupos oprimidos. Um fator estimulante para a formulação dessa teoria reside no fato de as mulheres negras terem sido consistentemente guetizadas no trabalho doméstico, o que contribuiu largamente para sua exploração econômica. No entanto essas mulheres puderam ver de uma perspectiva única aquilo que acontecia dentro das casas de "suas famílias brancas", sem nunca fazer parte delas. Assim, continuavam em seu lugar de outsiders economicamente exploradas, recebendo a nomenclatura de outsider within, termo que designa um tipo peculiar de marginalidade àquelas que se encontram em um espaço limiar.

Falar por si, encontrar a própria voz e se autodefinir é essencial para o empoderamento, sendo um meio de romper com hierarquias de poder que antes falavam por essas mulheres e definiam aos seus moldes o lugar a que deviam pertencer. Audre Lorde (I984 apud COLLINS, 200o, p. 36, tradução nossa) ressalta que "é axiomático que se não formos definidos por nós mesmos, seremos definidos pelos outros - para seu uso e em nosso detrimento". ${ }^{1}$ As experiências vividas e narradas pelas mulheres negras permitem criar uma interlocução

\footnotetext{
1 "It is axiomatic that if we do not define ourselves for ourselves, we will be defined by others - for their use and to our detriment" (LORDE 1984 apud COLLINS, 2000, p. 36).
} 
repleta de diferentes vozes sobre diferentes versões da verdade, afim de remontar coletivamente uma história. Alice Walker, autora vastamente citada por Patricia Hill Collins, comenta: ${ }^{2}$

Eu acredito que a verdade acerca de qualquer temática só vem à tona quando todos os lados da história são remontados e, em todos os seus sentidos, criam algo novo. Cada escritor escreve a parte que falta nas histórias de outros escritores. Eu estou atrás da história completa. ${ }^{3}$ (WALKER, 1983 apud COLLINS, 2000, p. 38, tradução nossa)

Havia tradição escrita entre as mulheres negras, porém apenas para aquelas que tiveram acesso à educação. O tempo, que também lhes era escasso por conta das longas jornadas de trabalho, as impedia de ter qualquer contato aprofundado com livros e romances. Por conseguinte encontrar textos de mulheres negras e pobres que transcendem as divisões entre as tradições orais e escritas é de extremo valor, como, por exemplo, a autora Alice Childress e a personagem ficcional Mildred, uma mulher negra e trabalhadora doméstica que fala sobre os mais diversos tópicos em 62 monólogos provocativos. No excerto de um de seus monólogos, a autora alega:

Eu não sou nada como um membro da família! A família come na sala de jantar, eu como na cozinha. Sua mãe pega emprestado sua toalha de mesa de renda para as visitas e você e seu filho entretêm seus amigos no salão, sua filha tira seu cochilo da tarde no sofá da sala de estar e o cachorro dorme nos seus lençóis de cetim... como você pode ver, eu não sou como um membro da família. ${ }^{4}$ (CHILDRESS, 1956 apud COLLINS, 2000, p. IO9, tradução nossa)

Nessa passagem, Childress cria uma versão ficcional, porém verossímil, das relações entre empregadas domésticas e seus patrões, elucubrando uma fala que tais empregadas vez ou outra gostariam de dizer aos seus empregadores. Em contraposição a Kathryn Stockett, autora de $A$ resposta, Childress é uma mulher negra, que está familiarizada com esse universo e, portanto, é capaz de representá-lo de maneira mais contundente. À época que foram escritos, os monólogos de Mildred tinham como propósito alcançar mulheres negras de diversas classes sociais e comunidades.

\footnotetext{
${ }^{2}$ Nota metodológica: optei por traduzir algumas das citações que estavam em inglês para que o texto pudesse ser acessível a todos, no entanto, também considerei importante manter suas versões originais pelo fato de acreditar que as vozes que devem ser ouvidas e lidas são aquelas que estão na versão original do texto e na língua que foram escritas por suas autoras, sem a traição da tradução.

3 "I believe that the truth about any subject only comes when all sides of the story are put together, and all their meanings make one new one. Each writer writes the missing parts to the other writer's story. And the whole story is what l'm after" (WALKER, 1983 apud COLLINS, 2000, p. 38).

4 "I am not just like one of the Family at all! The family eats in the dining room and I eat in the kitchen. Your mama borrows your lace tablecloth for her company and your son entertains his friends in your parlour, your daughter takes her afternoon nap on the living room couch and the puppy sleeps on your satin spread... so you can see I am not just like one of the family" (CHILDRESS, 1956 apud COLLINS, 2000, p. 109).
} 
Suas asserções estavam em consonância com as vozes silenciadas de seus leitores. Ademais a identidade de mulher negra, doméstica e working class não era do tipo que as pessoas estavam acostumadas a ver ilustrado em publicações.

Patricia Hill Collins (2000) aborda o tema do poder da autodefinição e, para ilustrá-lo, conta com depoimentos de mulheres negras que trabalhavam como domésticas, bem como estudos feitos por mulheres negras sobre essas mesmas trabalhadoras. O lugar de outsider within ocupado por elas fazia com que se familiarizassem com o modo de agir e com a linguagem do opressor. A empregada doméstica idosa Ella Surrey sumariza esse processo:

Nós sempre fomos as melhores atrizes do mundo... eu penso que somos muito mais espertas do que eles porque sabemos que temos que jogar o jogo. Nós sempre tivemos que viver duas vidas - uma para eles e outra para nós mesmas. ${ }^{5}$ (GWALTNEY, 1980 apud COLLINS, 2000, p. 97, tradução nossa)

Judith Rollins, intelectual negra, escreveu um livro no qual discorre sobre as tensões do trabalho doméstico e das relações nele envolvidas, reitera que as empregadas por ela entrevistadas apresentavam um notável senso do próprio valor ao habilmente desviar desses ataques psicológicos em sua humanidade, sua maturidade e sua dignidade, presentes nas tentativas de seus empregadores a convencê-las de aceitar ser definidas como inferiores (ROLLINS apud COLLINS, 2000). Bonnie Thorton Dill, outra intelectual negra que por sua vez também escreveu sobre trabalhadoras domésticas negras, constatou que muitas dessas mulheres não se permitiam subjugar. Uma delas dá a seguinte declaração:

Quando eu saí para trabalhar... minha mãe me disse: "Não deixe ninguém tirar vantagem de você. Defenda seus direitos, mas faça o trabalho corretamente. Se eles não lhe derem seus direitos, demande que eles a tratem direito. E se eles não o fizerem, peça demissão". (DILL apud COLLINS, 2000, p. 97, tradução nossa) ${ }^{6}$

Ao ler esses relatos de mulheres reais que viveram experiências reais, é fundamental colocar em xeque a versão romanceada de Kathryn Stockett. As mulheres descritas pelas autoras negras são mostradas como guerreiras, sobreviventes de uma época em que a escravidão ainda era uma realidade próxima, e a total ausência de direitos era seu cotidiano.

\footnotetext{
5 "We have always been the best actors in the world... I think that we are much more clever than they are because we know that we have to play the game. We've always had to live two lives - one for them and one for ourselves" (GWALTNEY, 1980 apud COLLINS, 2000, p. 97).

6 "When I went out to work... my mother told me, 'Don't let anybody take advantage of you. Speak up for your rights, but do the work right. If they don't give you your rights, you demand that they treat you right. And if they don't, then you quit. (DILL apud COLLINS, 2000, p. 97).
} 
O que Stockett oferece a elas em sua narrativa é uma vingança mesquinha contra a vilã da história e um livro escrito em parceria com uma jovem branca. As pesquisas que de fato tinham cunho sociológico feitas quase exclusivamente por mulheres negras nunca chegaram perto de ter a repercussão que seu romance teve. Talvez porque seja mais fácil acreditar que todo esse passado tenebroso foi apenas uma história inventada, e não a verdade.

O feminismo negro representa uma mudança paradigmática na maneira de pensar as relações de poder injustas. Assim, ao abarcar as opressões interseccionais (raça, gênero, classe, sexualidade e nacionalidade), essa teoria muda os contornos das relações de dominação e resistência.

A poeta negra Audre Lorde, em The transformation of silence into language and action, tece a seguinte reflexão:

Cada uma de nós está aqui agora porque de uma maneira ou de outra compartilhamos um comprometimento com a linguagem, com o poder da linguagem e em reclamá-la após ela ter sido instrumentalizada para trabalhar contra nós. $\mathrm{Na}$ transformação do silêncio em ação, é fundamentalmente necessário para cada uma de nós estabelecer ou examinar sua função nessa transformação e reconhecer dentro dela seu papel como vital.

Para aquelas que escrevem, é necessário escrutinar não apenas a verdade da qual falamos, como também a verdade daquela linguagem com a qual falamos. Para os outros, é compartilhar e disseminar essas palavras que são importantes para nós. Mas, primeiramente, para todas nós, é necessário ensinar aquelas verdades nas quais acreditamos e as quais conhecemos além de qualquer entendimento. Porque, apenas desse modo, poderemos sobreviver sendo parte de um processo de vida que é criativo e contínuo, que é crescimento. [...]

E onde as palavras das mulheres pranteiam para ser escutadas, cada uma de nós deve reconhecer sua responsabilidade de buscá-las, de lê-las, de compartilhá-las e de examiná-las em toda a sua pertinência para nossas vidas. Que não nos escondamos atrás de escárnios de separação que nos foram impostos e nós constantemente os aceitamos como nossos. ${ }^{\top}$ (LORDE, I984, p. 43, tradução nossa)

\footnotetext{
7 "Each of us in here now because in one way or another we share a commitment to language and the power of language and to the reclaiming of that language which has been made to work against us. In the transformation of silence into language and action, it is vitally necessary for each one of us to establish or examine her function in that transformation and to recognize her role as vital within that transformation."
} 
Portanto compreende-se a importância do protagonismo das mulheres negras tanto em suas histórias quanto em suas teorias e epistemologias. Certamente outras vozes dissonantes e consonantes não seriam excluídas, dado que enriquecem o debate e fortalecem a resistência contra a matriz dominante de pensamento, de discurso e de poder. Todavia existe um longo caminho a ser percorrido no que concerne ao entrelaçamento entre teoria e prática, pois, segundo Patricia Hill Collins (2000), teoria e prática devem caminhar juntas, com vistas a construir uma nova realidade social mais justa de forma coletiva e representativa para todas.

\section{Conclusão}

A autoridade e o lugar de fala subalternos se desvelam com a presença de inúmeras vozes no romance $A$ resposta, que, no entanto, emanam de uma única narradora que não faz parte do grupo que descreve, de modo que sua posição e seu ponto de vista ao contar essa história está impregnado de subjetividades e interpretações pessoais outras, absolutamente desiguais daquelas desempenhadas pelas personagens negras. A desvalorização do trabalho de intelectuais e autoras negras sobre o tema é preocupante, pois invisibiliza pesquisas, saberes e formas de ver que são mais próximas daquela realidade e que a relatam de maneira representativa.

O feminismo interseccional é determinante para o protagonismo. A representatividade é fundamental para o processo de desconstrução de papéis sociais opressivos previamente atribuídos a grupos marginalizados. No que tange à ruptura do silêncio, Audre Lorde (1984, p. 44) conclui sua obra com a seguinte afirmação:

O fato de estarmos aqui e de proferirmos essas palavras em uma tentativa de quebrar o silêncio e a ponte daquelas diferenças que se impõem entre nós, porque não é apenas a diferença que nos imobiliza, mas o silêncio. E ainda há muitos silêncios a serem quebrados. ${ }^{8}$ (tradução nossa)

Para que esses silêncios sejam quebrados é necessário que os meios literários e acadêmicos sejam cada vez mais povoados de mulheres negras. No que tange ao meio editorial, seria crucial a publicação, a divulgação e a disseminação dos trabalhos dessas mulheres para que a sociedade tenha acesso às suas histórias e às suas vozes; à sua maneira

\footnotetext{
"For those of us who write, it is necessary to scrutinize not only the truth of what we speak, but the truth of that language by which we speak. For others, it is share and spread those words that are meaningful to us. But primarily for us all it is necessary to teach those truths which we believe and know beyond understanding. Because in this way alone we can survive by taking part in a process of life that is creative and continuing, that is growth. [...]"

"And where the words of women are crying to be heard, we must each of us recognize our responsibility to seek those words out, to read them and share them and examine them in their pertinence to our lives. That we not hide behind the mockeries of separations that have been imposed upon us and which so often we accept as our own" (LORDE, 1984, p. 43).

8 "The fact that we are here and that I speak these words is an attempt to break that silence and bridge some of those differences between us, for it is not only difference which immobilizes us, but silence. And there are so many silences to be broken" (LORDE, 1984, p. 44).
} 
de ver, de criar e de narrar. Não apenas no que concerne a papéis subalternos históricos, como também todo o seu potencial criativo e criador como produtoras ativas de conhecimento artístico e acadêmico.

\section{Referências}

BEAUVOIR, S. de. O segundo sexo. Tradução Sérgio Miliet. 2. ed. Rio de Janeiro: Nova Fronteira, 2009. 2v.

BUTLER, J. Corpos que pesam: sobre os limites discursivos do "sexo". In: LOURO, G. L. (Org.). O corpo educado - pedagogias da sexualidade. Tradução Tomaz Tadeu da Sila. 2. ed. Belo Horizonte: Autêntica, 2000.

BUTLER, J. Problemas de gênero: feminismo e subversão da identidade. Tradução Renato Aguiar. 7. ed. Rio de Janeiro: Civilização Brasileira, 2014.

CLIFFORD, J. A experiência etnográfica - antropologia e literatura no século XX. 3. ed. Rio de Janeiro: Editora UFRJ, 2008.

COLLINS, P. H. Black feminist thought: knowledge consciousness, and the politics of empowerment. 2. ed. New York: Routledge, 2000.(Col. Perspectives on Gender)

CULLER, J. Teoria literária: uma introdução. Tradução Sandra Vasconcelos. São Paulo: Beca Produções Culturais, I999.

FOUCAULT, M. A ordem do discurso: aula inaugural no Collège de France, pronunciada em 2 de dezembro de 1970. Tradução Laura Fraga de Almeida Sampaio. 22. ed. São Paulo: Edições Loyola, 2012. (Col. Leituras Filosóficas)

FRANK, J. Pelo prisma russo: ensaios sobre literatura e cultura. Tradução Paula Cox Rolim, Francisco Achcar. São Paulo: EdUSP, 1992.

LORDE, A. Sister outsider: essays and speeches. Trumansburg, NY: Crossing Press, 1984. (Col. Crossing Press Feminist)

SPIVAK, G. C. Pode o subalterno falar? Tradução Sandra Regina Goulart Almeida, Marcos Pereira Feitosa, André Pereira Feitosa. Belo Horizonte: Editora UFMG, 20 Io.

STOCKETT, K. A resposta. Rio de Janeiro: Bertrand Brasil, 2012. 